\title{
PENGARUH STATE GOAL ORIENTATION TERHADAP PERFORMANCE DENGAN SELF-EFFICACY SEBAGAI VARIABEL PEMODERASI APLIKASI MATA KULIAH AKUNTANSI KEUANGAN LANJUTAN II
}

\author{
Sarwenda Biduri \\ Fakultas Ekonomi dan Bisnis, Universitas Muhammadiyah Sidoarjo \\ e-mail: sarwendabiduri@umsida.ac.id
}

\begin{abstract}
This goal of this research is want to know the effect of state goal orientation (SLGO) to performance and self-efficacy of accounting student. The sample in this study are students who have taken 2nd advanced financial accounting course which amounted to 136 respondents. Sample of this research is students who have taken 2 nd advanced financial accounting course. Sampling technique used in this research is purposive sampling. The analysis tool used is SPSS version 18.0, the analytical technique used is validity test, reliability test, classic assumption test, simple linear regression analisys, $t$-test, correlation coefficient, and determinant coefficient. The t-test results show that the effect of SLGO on self-efficacy has a significance value is 0.007 and 0.005 . The significance value of state performance goal orientation (SPGO) to self-efficacy is 0.130 and 0.596 . The significance value of self-efficacy on the performance of accounting students is 0.033 and 0.041 . It can be concluded that SLGO has an influence on self-efficacy, but state performance goal orientation has no effect on selfefficacy, and self-efficacy has an influence on accounting student performance.
\end{abstract}

Keywords: state learning goal orientation, state performance goal orientation, self-efficacy, performance of accounting student

\section{PENDAHULUAN}

Perguruan tinggi merupakan jenjang pendidikan tertinggi dalam sistem pendidikan nasional Indonesia yang diharapkan mampu menciptakan manusia berkualitas dan berintelektual sehingga dapat mengubah masa depan bangsa yang lebih baik. Maka dari itu, mahasiswa yang belajar di perguruan tinggi dituntut tidak hanya memiliki kemampuan secara hardskill maupun softskill tetapi juga kerangka pikir serta sikap mental dan kepribadian tertentu sehingga mempunyai pengetahuan yang luas dalam menghadapi masalah-masalah global.

Saat ini bidang akuntansi merupakan salah satu bidang yang menjadi perhatian berat. Pembelajaran akuntansi yang diterapkan di beberapa perguruan tinggi pada tingkat Strata Satu (S1) menjadi beberapa pilihan modal mahasiswa menuju profesi dunia akuntan publik dan berniat dalam menciptakan alumnus berdedikasi tinggi dengan etika beserta moral yang baik. Nilai-nilai profesi dan etika akuntan diperkenalkan melalui bermacam upaya untuk mahasiswa. Cara ekspansi pendidikan akuntansi dilandaskan etika tersebut yang dibutuhkan dengan diadakannya feedback yakni apakah pembelajaran akuntansi di Indonesia sudah mewujudkan mahasiswa akuntansi yang bermutu tinggi. Hal tersebut disebabkan karena munculnya berkembangnya pasar modal, pertambahan ekonomi dan kecanggihan teknologi informasi diikuti perubahan lain.

Faktor utama yang menunjang kesuksesan mahasiswa dalam memperoleh prestasinya berasal dari personal individunya. Niat, keyakinan, dan kesungguhan merupakan motivasi yang baik dalam mencapai tujuan. Dalam penelitiannya, Ilyas, dkk. (2007) menyatakan bahwa kesuksesan (kinerja) diperkuliahan selama di kelas merupakan faktor lebih dari mahasiswa (student).

Selama dekade terakhir ini, model orientasi tujuan menjadi perhatian oleh sejumlah peneliti. Orientasi tujuan atau goal orientation merupakan salah satu usaha yang dicoba untuk mendapatkan atau menggapai tingkat kinerja khusus dengan cara implisit yang dinyatakan oleh beberapa individu (Ilyas, dkk., 2007). Goal orientation yang dimaksud dalam penelitian ini yaitu usaha (effort) mahasiswa dalam meggapai suatu keberhasilan, serta upaya mereka saat melakukan metode dan 
tugas yang mereka libatkan didalamnya. State goal orientation yang dimaksud ialah pernyataan baik diucapkan maupun dituliskan oleh mahasiswa akuntansi mengenai orientasi tujuan (goal orientation) dalam dirinya.

Dalam praktiknya, tidak banyak mahasiswa akuntansi memiliki orientasi tujuan (goal orientation) yang jelas. Mereka lebih cenderung bingung mengenai alasan dan tujuan mereka memilih program akuntansi. Hal-hal semacam ini tentunya bisa memberikan dampak pada hasil belajar atau kinerja (performance) mahasiswa menjadi tidak terarah dan tidak sesuai tujuan pendidikan Indonesia.

Berdasarkan latar belakang tersebut, maka rumusan masalah dalam penelitian ini adalah apakah State Goal Orieintation berpengaruh terhadap Performance dengan Self Efficacy sebagai Variabel Pemoderasi Aplikasi Pada Mata Kuliah Akuntansi Keuangan Lanjutan II?

\section{Goal Orientation (Orientasi Tujuan)}

Rono (2012) mengemukakan teori bahwa terdapat dua buah pola perilaku yang mencerminkan goal orientation yang berbeda. Dua jenis goal orientation tersebut ialah learning goal orientation dan performance goal orientation. Penjelasan mengenai keduanya adalah sebagai berikut:

\section{a. Learning Goal Orientation (LGO)}

Mahasiswa yang menggunakan pendekatan learning goal orientation memiliki sebuah tujuan dalam belajar yaitu untuk mempelajari keahlian dan ilmu baru. Karakteristik mahasiswa ini adalah memiliki daya tahan ketika dihadapkan pada suatu masalah, mau mencoba berbagai strategi pemecahan masalah, serta menikmati tantangan. Berkaitan dengan faktor-faktor lain yang mempengaruhi prestasi, learning goal orientation dapat memprediksi keberhasilan prestasi akademis lebih baik dibandingkan dengan prediksi dari kepribadian dan intelejensi seseorang.

Ketika seorang mahasiswa mengejar learning goal orientation, maka mahasiswa tersebut bertujuan untuk mengembangkan kompetensi dengan cara memperoleh keahlian dan pengetahuan baru. Mereka menilai dan mau melakukan berbagai aktivitas yang dapat meningkatkan pengetahuan mereka, serta sebuah upaya (effort) dipandang sebagai hal yang positif, dan cara yang positif untuk mencapai tujuan mereka. Sebuah kesalahan akan dianggap sebagai hal yang normal dalam pembelajaran.

b. Performance Goal Orientation (PGO)
Mahasiswa yang menggunakan pendekatan performance goal orientation lebih bertujuan mengejar hasil daripada proses. Mahasiswa ini menginginkan penilaian yang baik terhadap performanya dan menghindari penilaian negatif dari orang lain. Mahasiswa dengan performance goal orientation ini lebih bertujuan untuk menunjukkan kemampuan mereka kepada mahasiswa lain. Bagi mereka, sebuah upaya (effort) dipandang secara negatif. Mahasiswa dengan performance goal melihat intelejensi sebagai hal yang menetap, kemudian mereka juga menghindari penilaian negatif dari orang lain, serta mereka lebih termotivasi secara eksternal dan sebuah kesalahan diartikan oleh mahasiswa tersebut sebagai ketidakmampuan.

\section{Self-Efficacy (Efikasi Diri)}

Menurut Nadhiroh (2010), self-efficacy adalah keyakinan dalam diri seseorang dalam menuntaskan sebuah tugas pada tingkat tertentu yang dipengaruhi dari tindakan personalitas terhadap pencapaian tujuan. Self - efficacy adalah sebagian dari kemampuan diri individu yang dikelola. Konsep ini bertujuan untuk menampakkan kecakapan individu yang diacu dari persepsi kemampuan dalam menerapkan dan mengorganisasikan tindakan. Jadi, dapat diartikan bahwa self-efficacy merupakan kepercayaan individu terhadap kemampuan personalitasnya dalam mengorganisasi sesuatu tugas guna mencapai suatu tujuan.

\section{Performance Mahasiswa Akuntansi}

Performance atau biasa disebut dengan kinerja yang berarti hasil kerja seorang pekerja, sebuah proses manajemen atau suatu entitas yang dapat ditunjukkan bukti secara konkrit dan mampu diukur secara keseluruhan hasil kerjanya. Berkinerja diartikan dengan memperlihatkan prestasi atau berkemampuan. Jadi, kinerja dapat diartikan dengan hasil/ tingkat ketercapaian upaya seseorang dengan menyeluruh selama periode waktu saja ketika melaksanakan tugas berbanding dalam beberapa kemungkinan, misalnya standar dari hasil kerja, target, atau sasaran atau kriteria yang telah ditentukan terlebih dahulu dan telah disepakati bersama.

Yang dimaksud dengan kinerja mahasiswa akuntansi di sini ialah hasil atau proses yang diperoleh oleh mahasiswa akuntansi selama menempuh pendidikan di perguruan tinggi maupun sesudahnya. Mahasiswa akuntansi dituntut untuk dapat menguasai teori dan praktik mengenai 
akuntansi baik berkenaan dengan penyusunan laporan keuangan, perhitungan pajak hingga pemeriksaan (audit).

\section{Kerangka Konseptual}

Berikut peneliti menyajikan bentuk paradigma penelitian dalam penelitian ini adalah sebagaiberikut:

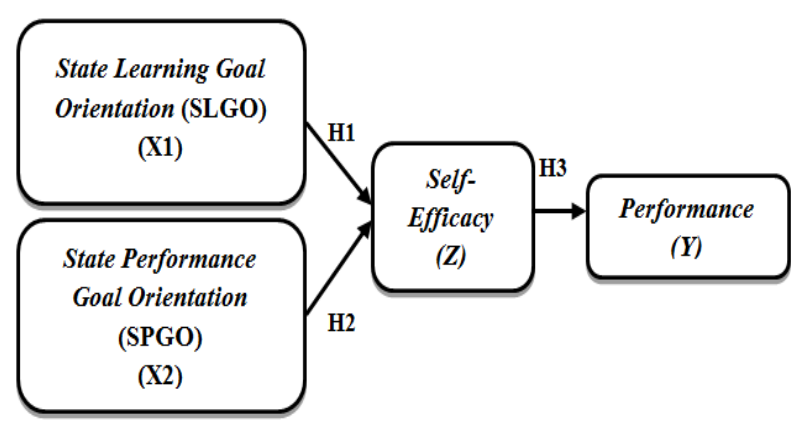

\section{Gambar 1 \\ Kerangka Konsptual}

$H_{1}$ : State learning goal orientation berpengaruh terhadap self-efficacy.

$\mathrm{H}_{2}$ : State performance goal orientation berpengaruh terhadap self-efficacy.

$\mathrm{H}_{3}$ : Self-efficacy berpengaruh terhadap performance

\section{METODE PENELITIAN}

\section{Jenis Penelitian}

Penelitian ini menggunakan oendekatan penelitian kuantitaif. Metode penelitian kuantitatif didefinisikan sebagai metode penelitian yang berlandaskan pada filsafat positivisme, digunakan untuk meneliti populasi atau sampel tertentu dan pengumpulan data menggunakan instrumen penelitiaa serta analisis data bersifat kuantitatif/statistik diperuntukkan menguji hipotesis yang telah ditetapkan (Sugiyono, 2014). Penelitian ini dilakukan di Prodi Akuntansi Fakultas Ekonomi dan Bisnis Universitas Muhammadiyah Sidoarjo yang terletak di Jalan Raya Mojopahit No 666 B, Sidoarjo.

\section{Definisi Operasional dan Pengukuran Variabel}

\section{State Learning Goal Orientation $\left(\mathrm{X}_{1}\right)$}

Variabel state learning goal orientation (SLGO) di sini diukur dengan menggunakan instrumen penelitian yang dilakukan oleh Ilyas, dkk. (2007) dengan tambahan modifikasi instrumen dari penelitian (Rono, 2012). Instrumen state learning goal orientation $\left(\mathrm{X}_{1}\right)$ ini terdiri dari 6 (enam) item pertanyaan.

2. State PerformanceGoal Orientation $\left(\mathrm{X}_{2}\right)$
Variabel state performance goal orientation (SPGO) di sini juga diukur dengan menggunakan instrumen penelitian yang dilakukan oleh Ilyas, dkk. (2007) dan tambahan modifikasi instrumen dari penelitian (Rono, 2012). Instrumen state performance goal orientation $\left(\mathrm{X}_{2}\right)$ ini juga terdiri dari 6 (enam) item pertanyaan.

3. Self-Efficacy $(\mathrm{Z})$

Dalam penelitian ini, peneliti menggunakan self-efficacy sebagai variabel dependen (Z). Adapun alat ukur yang digunakan merujuk pada penelitian Ilyas, dkk. (2007) yakni dengan meminta responden menuliskan keyakinan mereka dalam memperoleh hasil/nilai yang baik (>85) pada saat UTS (Ujian Tengah Semester) dan dinyatakan dalam persentase $(\%)$.

4. Performance Mahasiswa Akuntansi (Y)

Performance mahasiswa akuntansi di sini diukur dengan menggunakan dokumen berupa hasil/nilai akhir pada UTS (Ujian Tengah Semester) yang diperoleh oleh mahasiswa akuntansi. Instrumen ini merujuk pada penelitian sebelumnya, yaitu penelitian oleh (Ilyas, dkk., 2007).

\section{Populasi dan Sampel}

Dalam penelitian ini, populasi yang digunakan peneliti adalah mahasiswa Program Studi Akuntansi Fakultas Ekonomi \& Bisnis di Universitas Muhammadiyah Sidoarjo. Sedangkan sampel dibagian atas jumlah dan karakteristik yang didapatkan oleh populasi demikian (Sugiyono, 2010). Sampel yang digunakan oleh peneliti adalah mahasiswa program studi akuntansi yang sedang menempuh mata kuliah Akuntansi Keuangan Lanjutan (AKL) II baik yang mengikuti kelas pagi maupun malam. Jumlah sampel yang digunakan dalam penelitian ini berjumlah 246. Alasan peneliti memilih mahasiswa yang sedang menempuh mata kuliah AKL II sebagai sampel penelitian dikarenakan mata kuliah ini dianggap sebagai puncak dari mata kuliah lainnya dalam program studi Akuntansi di Universitas Muhammadiyah Sidoarjo.

\section{Jenis dan Sumber Data}

Data yang digunakan dalam penelitian ini merupakan data primer dan sekunder. Data primer merupakan data yang didapatkan dari responden melalui kuesioner, kelompok fokus, dan panel, atau juga data hasil wawancara peneliti dengan narasumber (Sujarweni 2015). Data primer yang dalam penelitian ini digunakan untuk menggambarkan variabel state learning goal 
orientation, state performance goal orientation, dan self-efficacy. Sementara itu, data sekunder diperoleh dari dokumen berupa hasil Ujian Tengah Semester (UTS) mahasiswa akuntansi yang diperoleh dari dosen pengampu mata kuliah Akuntansi Keuangan Lanjutan (AKL) II.

\section{Teknik Pengumpulan Data}

Penggunaan angket dalam penelitian kali ini digunakan untuk teknik pengumpulan data. Kuesioner merupakan alat yang diberikan responden kepada peneliti berupa lembaran kertas yang didalamnya terdapat pernyataan maupun pertanyaan dimana alat tersebut merupakan teknik pengumpulan data (Sugiyono, 2014). Teknik pengumpulan data yang dilakukan dari penelitian ini ialah Sampling Purposive Methods. Sampling Purposive yaitu teknik menentukan sampel berdasar kriteria-kriteria terpilih (Sujarweni, 2015).

Adapun kuesioner yang dibagikan menggunakan Skala Likert yang diberi rentang nilai antara 1 - 4. Skala Likert digunakan untuk mengukur sikap, opini, dan rekognisi individu atau kelompok tentang fenomena social (Sujarweni, 2015). Dengan Skala Likert, variabel yang akan diukur dipaparkan menjadi indikator variabel kemudian dijadikan sebagai tolok ukur untuk membuat butir-butir pertanyaan dan disediakan dalam bentuk skoring. Adapun format skoring dalam Skala Likert tersebut adalah:

Tabel 1

Pilihan Jawaban dan Scoring Kuesioner

\begin{tabular}{cc}
\hline Keterangan & Skor \\
\hline Sangat Setuju (SS) & 4 \\
\hline Setuju (S) & 3 \\
\hline Tidak Setuju (TS) & 2 \\
\hline Sangat Tidak Setuju (STS) & 1
\end{tabular}

Sumber: Data diolah

Selain menyebar kuesioner kepada responden, peneliti juga mengumpulkan data berupa dokumen hasil Ujian Tengah Semester (UTS) mata kuliah AKL (Akuntansi Keuangan Lanjutan) 2 yang diperoleh mahasiswa akuntansi. Adapun dokumen tersebut diterima dari dosen pengampuh mata kuliah tersebut.

\section{Teknik Analisis Data dan Uji Hipotesis}

Dalam penelitian ini pengolahan dilakukan dengan bantuan SPSS (Statistical Product and Service Solutions) versi 18.0 sebagai alat dalam menganalisis data. Analisis diawali dengan melakukan uji kualitas data yang terdiri atas uji validitas dan uji realibilitas pada setiap item pertanyaan dalam kuesioner. Selanjutnya data yang terkumpul dilakukan analisis regresi linier sederhana dan uji hipotesis berupa uji t, koefisien korelasi, dan koefisien determinasi.

\section{PEMBAHASAN}

\section{Uji Validitas}

Uji validitas data di sini dilakukan guna menguji variabel state learning goal orientation $\left(\mathrm{X}_{1}\right)$ dan state performance goal orientation $\left(\mathrm{X}_{2}\right)$. Uji validitas tersebut masing-masing dilakukan sebanyak dua kali yakni pada saat ujian tengah semester. Semua variabel yang digunakan dalam penelitian dinyatakan valid. Berikut ini disajikan hasil uji validitas variabel $X_{1}$ dan $X_{2}$ pada ujian tengah semester dalam Tabel 2:

Tabel 2 Hasil Uji Validitas

\begin{tabular}{cccc}
\hline Variabel & r tabel & r hitung & Keterangan \\
\hline \multicolumn{2}{l}{ State Learning } & Goal Orientation $\left(\mathbf{X}_{1}\right)$ & \\
\hline $\mathrm{X} 1.1$ & 0,30 & 0,311 & Valid \\
\hline $\mathrm{X} 1.2$ & 0,30 & 0,413 & Valid \\
\hline $\mathrm{X} 1.3$ & 0,30 & 0,388 & Valid \\
\hline $\mathrm{X} 1.4$ & 0,30 & 0,382 & Valid \\
\hline $\mathrm{X} 1.5$ & 0,30 & 0,395 & Valid \\
\hline $\mathrm{X} 1.6$ & 0,30 & 0,302 & Valid \\
\hline
\end{tabular}

State Performance Goal Orientation $\left(\mathrm{X}_{2}\right)$

\begin{tabular}{llll}
\hline $\mathrm{X} 2.1$ & 0,30 & 0,562 & Valid \\
\hline $\mathrm{X} 2.2$ & 0,30 & 0,515 & Valid \\
\hline $\mathrm{X} 2.3$ & 0,30 & 0,335 & Valid \\
\hline $\mathrm{X} 2.4$ & 0,30 & 0,650 & Valid \\
\hline $\mathrm{X} 2.5$ & 0,30 & 0,491 & Valid \\
\hline $\mathrm{X} 2.6$ & 0,30 & 0,535 & Valid \\
\hline
\end{tabular}

Sumber: Data Diolah dengan SPSS 18.0 


\section{Uji Reliabilitas}

Dalam penelitian ini, uji reliabilitas dilakukan secara bersama-sama terhadap seluruh butir pernyataan dengan menggunakan program SPSS versi 18.00. Jika nilai Cronbach's Alpha > 0,60 maka reliabel. Demikian sebaliknya, jika nilai Cronbach's Alpha < 0,60 maka dinyatakan tidak reliabel. Adapun hasil uji reliabiltas tersebut ditampilkan dalam Tabel 3 berikut ini:

Tabel 3

Hasil Uji Reliabilitas

\begin{tabular}{ccc}
\hline Variabel & $\begin{array}{c}\text { Cronbach's } \\
\text { Alpha }\end{array}$ & $\begin{array}{c}\text { N of } \\
\text { Item }\end{array}$ \\
\hline $\begin{array}{c}\text { State Learning Goal } \\
\text { Orientation }\left(\mathrm{X}_{1}\right)\end{array}$ & 0,635 & 6 \\
\hline $\begin{array}{c}\text { State Performance Goal } \\
\text { Orientation }\left(\mathrm{X}_{2}\right)\end{array}$ & 0,768 & 6 \\
\hline Sur
\end{tabular}

Sumber: Data Diolah dengan SPSS 18.0

Berdasarkan hasil uji reliabilitas dalam Tabel 3 menggnakan SPSS 18.0 diketahui bahwa nilai Cronbach Alpha pada $\mathrm{X}_{1}$ dan $\mathrm{X}_{2}$ lebih dari 0,6 sehingga dapat dikatakan data bersifat reliabel.

\section{Analisis Regresi Sederhana}

Tabel 4

Analisis Regresi Linier Sederhana Model 1

\begin{tabular}{lcccc}
\hline \multirow{2}{*}{ Model } & \multicolumn{2}{c}{$\begin{array}{c}\text { Unstandardized } \\
\text { Coefficient }\end{array}$} & t & Sig \\
\cline { 2 - 4 } & $\mathrm{B}$ & $\begin{array}{c}\text { Std. } \\
\text { Error }\end{array}$ & & \\
\hline (Constant) & 0,526 & 0,104 & 5,079 & 0,000 \\
\hline SLGO & 0,015 & 0,005 & 2,748 & 0,007 \\
\hline
\end{tabular}

Sumber: Data Diolah dengan SPSS 18.0

Berdasarkan Tabel 4 didapatkan model persamaan regresi sebagai berikut:

$$
\begin{gathered}
Z=\alpha+\beta_{1} X 1+e \\
Z=0,526+0,015+e
\end{gathered}
$$

Keterangan:

$$
\begin{array}{ll}
\mathrm{Z} & =\text { Self-Efficacy } \\
\mathrm{X}_{1} & =\text { SLGO } \\
\alpha & =\text { Intercept } \text { (konstanta) } \\
\beta_{1} & =\text { Koefisien regresi } \mathrm{X}_{1} \\
\mathrm{e} & =\text { Kesalahan pengganggu }
\end{array}
$$
bahwa:

Hasil dari persamaan diatas, dapat diterangkan

a. Nilai konstanta yaitu 0,526 . Hal ini bermaksud bahwa tanpa adanya pengaruh state learning goal orientation (SLGO) selaku variabel independen, maka nilai variabel dependennya yaitu self-efficacy tetap konstan sebesar 0,526.

b. Nilai koefisien dari regresi dari SLGO sebesar 0,015 . Artinya jika setiap kenaikan 1 satuan variabel SLGO maka mengakibatkan kenaikan variabel self-efficacy sebesar 0,015.

\section{Tabel 5}

Analisis Regresi Linier Sederhana Model 2

\begin{tabular}{lcccc}
\hline \multirow{2}{*}{ Model } & \multicolumn{2}{c}{ Unstandardized } \\
& Coefficient & \multirow{2}{*}{$\mathrm{t}$} & \multirow{2}{*}{ Sig } \\
\cline { 2 - 4 } & $\mathrm{B}$ & $\begin{array}{c}\text { Std. } \\
\text { Error }\end{array}$ & & \\
\hline (Constant) & 0,666 & 0,066 & 10,032 & 0,000 \\
\hline SPGO & 0,009 & 0,004 & 2,193 & 0,007 \\
\hline Sumber: Data Diolah dengan SPSS 18.0 &
\end{tabular}
persamaan regresi sebagai berikut:

$$
\begin{gathered}
Z=\alpha+\beta_{2} X_{2}+e \\
Z=0,666+0,009+e
\end{gathered}
$$

Keterangan:

$$
\begin{array}{ll}
\mathrm{Z} & =\text { Self-Efficacy } \\
\mathrm{X}_{2} & =\text { SPGO } \\
\alpha & =\text { Intercept } \text { (konstanta) } \\
\beta_{2} & =\text { Koefisien regresi } \mathrm{X}_{2} \\
\mathrm{e} & =\text { Kesalahan pengganggu }
\end{array}
$$
bahwa:

Hasil dari persamaan diatas, dapat diterangkan

a. Nilai konstanta yaitu 0,666 . Hal ini berarti bahwa tanpa adanya pengaruh state perfromance goal orientation (SPGO) selaku variabel independen, maka nilai variabel dependennya yaitu self-efficacy tetap konstan sebesar 0,666.

b. Nilai koefisien dari regresi dari SPGO sebesar 0,009 . Artinya jika setiap kenaikan 1 satuan variabel SLGO maka mengakibatkan kenaikan variabel self-efficacy sebesar 0,009.

Berdasarkan Tabel 6 didapatkan model persamaan regresi sebagai berikut:

$$
\begin{gathered}
\mathrm{Y}=\alpha+\beta_{3} \mathrm{Z}+\mathrm{e} \\
\mathrm{Y}=89,879+19,546+\mathrm{e}
\end{gathered}
$$

Keterangan:

$\mathrm{Y}=$ Performance

$\alpha \quad=$ Intercept (konstanta)

$\beta_{3}=$ Koefisien regresi $\mathrm{Z}$ 
$\mathrm{e} \quad=$ Kesalahan pengganggu

Tabel 6

Analisis Regresi Linier Sederhana Model 3

\begin{tabular}{lcccc}
\hline \multirow{4}{*}{ Model } & \multicolumn{3}{c}{ Unstandardized } \\
& Coefficient & \multirow{2}{*}{ t } & Sig \\
\cline { 2 - 3 } & $\mathrm{B}$ & $\begin{array}{c}\text { Std. } \\
\text { Error }\end{array}$ & & \\
\hline (Constant) & 89,879 & 7,424 & 12,107 & 0,000 \\
\hline SPGO & 19,564 & 9,061 & 2,157 & 0,007 \\
\hline
\end{tabular}

Sumber: Data Diolah dengan SPSS 18.0 bahwa:

Hasil dari persamaan diatas, dapat diterangkan

a. Nilai konstanta yaitu 89,879 . Hal ini berarti tanpa adanya self-efficacy selaku variabel independen, maka nilai variabel dependennya yaitu performance tetap konstan sebesar 89,879 .

b. Nilai koefisien dari self-efficacy sebesar 19,546. Artinya jika setiap kenaikan 1 satuan variabel self-efficacy maka mengakibatkan kenaikan variabel performance sebesar 19,546.

\section{Uji Hipotesis}

\section{Uji t (Uji Parsial)}

Uji ini untuk mengetahui apakah variabel bebas mempunyai pengaruh secara parsial terhadap variabel terikat. Pengujian hipotesisi dilakukan dengan melihat nilai signifikansi t masing-masing variabel pada output hasil regresi menggunakan SPSS 18.0 dengan significance level $0,05(\alpha=5$ $\%$ ). Hasil uji t (uji parsial) dalam penelitian ini adalah sebagai berikut:

\section{Tabel 7}

\section{Hasil Uji Hipotesis}

\begin{tabular}{lccl}
\hline \multicolumn{1}{c}{ Variabel } & $\mathbf{t}$ & Sig. & Kesimpulan \\
\hline SLGO & 2,748 & 0,007 & Signifikan \\
\hline SPGO & 1,193 & 0,130 & $\begin{array}{l}\text { Tidak } \\
\text { signifikan }\end{array}$ \\
\hline Self Eficacy & 2,157 & 0,033 & Signifikan \\
\hline
\end{tabular}

Sumber: Data Diolah dengan SPSS 18.0

Sesuai dengan hasil perhitungan uji $t$ menggunakan program SPSS 18.0 diperoleh $\mathrm{t}$ hitung sebesar 2,748 pada Tabel 7 uji t model 1 . Hal ini menunjukkan bahwa $\mathrm{t}$ hitung lebih besar dari $\mathrm{t}$ tabel yaitu 1,656. Sedangkan nilai signifikansi sebesar 0,007 ini lebih kecil daripada $\alpha$ yaitu 0,05 . Karena $\mathrm{t}_{\text {hitung }}>\mathrm{t}$ tabel dan sig $<\alpha$ baik pada model 1 maka dapat ditarik kesimpulan bahwa state learning goal orientation $\left(\mathrm{X}_{1}\right)$ berpengaruh terhadapself-efficacy. Dengan demikian $\mathrm{H}_{1}$ diterima.
Sesuai dengan hasil perhitungan uji $t$ menggunakan program SPSS 18.0 dalam Tabel 7 uji $\mathrm{t}$ diperoleh $\mathrm{t}$ hitung sebesar 1,193. Hal ini menunjukkan bahwa $\mathrm{t}_{\text {hitung }}$ lebih rendah dari $\mathrm{t}_{\text {tabel }}$ yaitu 1,656. Sedangkan nilai signifikansi sebesar 0,13 ini lebih besar daripada $\alpha$ yaitu 0,05 . Karena t hitung $<\mathrm{t}_{\text {tabel }}$ dan sig $>\alpha$ baik pada model 2 maka dapat ditarik kesimpulan bahwa state performance goal orientation $\left(\mathrm{X}_{2}\right)$ tidak berpengaruh terhadapself-efficacy. Dengan demikian $\mathrm{H}_{2}$ ditolak.

Sesuai dengan hasil perhitungan uji $t$ menggunakan program SPSS 18.0 diperoleh $\mathrm{t}_{\text {hitung }}$ sebesar 2,157 pada Tabel 7 uji t model 1. Hal ini menunjukkan bahwa $\mathrm{t}$ hitung lebih besar dari $\mathrm{t}$ tabel yaitu 1,656. Sedangkan nilai signifikansi sebesar 0,033 ini lebih kecil daripada $\alpha$ yaitu 0,05 . Karena $\mathrm{t}_{\text {hitung }}>\mathrm{t}$ tabel dan sig $<\alpha$ baik pada model 3 maka dapat ditarik kesimpulan bahwa self-efficacy (Z) berpengaruh terhadapperformance (Y). Dengan demikian $\mathrm{H}_{3}$ diterima.

2. Koefisien Korelasi (R) dan Koefisien Determinasi $\left(\mathrm{R}^{2}\right)$

Dalam Tabel 8 koefisien korelasi model 1 memiliki nilai 0,891 . Hal ini menunjukkan bahwa SLGO $\left(\mathrm{X}_{1}\right)$ memiliki pengaruh yang kuat terhadap self-efficacy (Z) karena nilai koefisien korelasi mendekati angka 1 . Untuk model 2 nilai koefisien korelasi sebesar 0,168. Hal ini menunjukkan bahwa SPGO $\left(\mathrm{X}_{2}\right)$ memiliki pengaruh yang lemah terhadap self-efficacy (Z) karena koefisien korelasi jauh dari angka 1. Untuk model 3 nilai koefisien korelasi sebesar 0,946. Hal ini menunjukkan bahwa self-efficacy (Z) memiliki pengaruh yang kuat terhadap performance $(\mathrm{Y})$ karena nilai koefisien korelasi mendekati angka 1.

\section{Tabel 8}

\begin{tabular}{ccc}
\multicolumn{3}{c}{ Koefisien Korelasi dan Determinasi } \\
\hline Model & R & R Square \\
\hline 1 & 0,891 & 0,530 \\
\hline 2 & 0,168 & 0,035 \\
\hline 3 & 0,946 & 0,334 \\
\hline
\end{tabular}

Sumber: Data Diolah dengan SPSS 18.0

Dalam Tabel 8 diperoleh nilai koefisien determinan (R Square) model 1 sebesar 0,530 atau setara dengan 53\%. Hasil ini menunjukkan bahwa self-efficacy dipengaruhi oleh SLGO sebesar 53\% dan sisanya sebesar $47 \%$ dipengaruhi oleh variabel lainnya di luar model regresi ini. Untuk model 2, 
diperoleh nilai $R$ Square sebesar 0,035 atau setara dengan $3,5 \%$. Hasil ini menunjukkan bahwa selfefficacy dipengaruhi oleh SPGO hanya sebesar $3,5 \%$ dan sisanya sebesar $96,5 \%$ dipengaruhi oleh variabel lainnya di luar model regresi ini. Untuk model 3, menunjukkan nilai $R$ Square sebesar 0,334 atau setara dengan $33,4 \%$. Hasil ini menunjukkan bahwa performance dipengaruhi oleh self-efficacy sebesar 33,4\% dan sisanya $66.6 \%$ dipengaruhi oleh variabel lainnya di luar model regresi ini.

Dalam penelitian ini diperoleh hasil bahwa SLGO memiliki berpengaruh terhadap selfefficacy. Hal ini tentunya mendukung penelitian yang dilakukan oleh Ilyas, dkk (2007) yang menyatakan bahwa SLGO berpengaruh pada selfefficacy di mana signifikan pada alpha 5\%. Dugaan awal dalam penelitian ini adalah menganggap bahwa SPGO berpengaruh negatif pada self-efficacy. Namun berdasarkan hasil analisis menggunakan SPSS versi 18.0 diketahui bahwa SPGO tidak memiliki pengaruh pada selfefficacy. Selain itu, hasil ini juga mendukung penelitian (Ilyas, dkk., 2007). Menurut Ilyas, orientasi hasil mahasiswa didasarkan pada proses perkuliahan bukan didasarkan pada end result. Setelah dilakukan analisis menggunakan program SPSS 18.0 diketahui bahwa dalam penelitian ini menunjukkan bahwa self-efficacy berpengaruh terhadap performance mahasiswa akuntansi di Universitas Muhammadiyah Sidoarjo. Hasil ini sekaligus menguatkan penelitian Ilyas, dkk. (2007) yang menyatakan adanya pengaruh self-efficacy terhadap performance di mana signifikan pada alpha $5 \%$.

\section{PENUTUP}

\section{Kesimpulan}

1. State learning goal orientation (SLGO) berpengaruh terhadap self-efficacy. Artinya mahasiswa akuntansi di Universitas Muhammadiyah Sidoarjo yang orientasi tujuannya pada pengembangan potensi akan memiliki self-efficacy yang tinggi pula.

2. State performance goal orientation (SPGO) tidak berpengaruh terhadap self-efficacy. Hal ini menunjukkan bahwa mahasiswa akuntansi tidak mendasarkan orientasinya pada hasil akhir atau nilai melainkan lebih pada proses pembelajaran.

3. Self-efficacy berpengaruh terhadap performance. Jadi, mahasiswa akuntansi yang memiliki tingkat efikasi diri atau kepercayaan atas kemampuan sendiri yang tinggi maka memiliki kinerja yang baik.

\section{SARAN}

1. Penelitian selanjutnya diharapkan dapat memperluas jumlah sampel yang digunakan. Bukan sekedar di lingkup Universitas Muhammadiyah Sidoarjo saja, namun diharapkan penelitian selanjutnya ditambahkan sampel dari perguruan tinggi lainnya, dapat dibandingkan hasil antara mahasiswa akuntansi Universitas Muhammadiyah Sidoarjo mahasiswa akuntansi dari perguruan tinggi lainnya.

Disarankan kepada pihak kampus khususnya jajaran dosen pengampuh mata kuliah akuntansi khususnya akuntansi keuangan lanjutan agar bisa memotivasi mahasiswa supaya mereka memiliki orientasi tujuan pada proses pembelajaran bukan sekedar hasil akhir atau nilai yang bagus saja.

\section{DAFTAR PUSTAKA}

Ghozali, Imam. 2007. Aplikasi Analisis Multivariate dengan Program SPSS. Badan Penerbit Universitas Diponegoro: Semarang.

Ilyas, Meifida, dkk. 2007. Peran Pernyataan Orientasi Tujuan (State Goal Orientation) dalam Pengajaran di Kelas terhadap Proses Pencapaian Kinerja Mahasiswa Akuntansi di Perguruan Tinggi. Simposium Nasional Akuntansi X. Penerbit Unhas Makassar

Nadhiroh, Siti Asih. 2010. Pengaruh Kompleksitas Tugas, Orientasi Tujuan, dan Self-Efficacy Terhadap Auditor dalam Pembuatan Audit Judgment (Studi pada Kantor Akuntan Publik di Semarang). Skripsi Program Sarjana Fakultas Ekonomi UNDIP. Semarang.

Rono, M.K. 2012. Hubungan Antara Goal Orientation dan Prestasi Akademis pada Mahasiswa Fakultas Psikologi Universitas Indonesia. Skripsi Program Sarjana Fakultas Psikologi UI. Depok.

Sugiyono. 2014. Metode Penelitian Pendidikan:Pendekatan Kuantitatif, Kualitatif, dan R\& D. Penerbit Alfabeta. Bandung.

Sujarweni, V. Wiratna. 2015. Metodologi Penelitian Bisnis \& Ekonomi. Pustaka Baru Press. Yogyakarta. 